\title{
Briefing: Infrastructure projects and the flexibility of urban infrastructure
}

Esteban Rossi-Hansberg PhD

Theodore A. Wells '29 Professor of Economics, Department of Economics and Woodrow Wilson School, Princeton University, Princeton, NJ, USA (erossi@princeton.edu)

An economic evaluation of large infrastructure projects requires predictions to be developed about the evolution of the economic environment as well as of the effect of the project on economic dynamics. A set of new quantitative economic models can help with this task. A proper evaluation can not only make projects more profitable in terms of private and social returns, but also prevent whole regions from falling into decline. The author discusses the case of declining cities and the role that road and other forms of infrastructure have played in the persistence of their downfall. Particular emphasis is put on the distorted urban structure of the city of Detroit in the USA and the potential gains from policies that can improve its current structure. The author argues that a policy based on 'development guarantees' by the city government or other outside parties can help ameliorate the current negative impact of an infrastructure built for a city that used to have a population that was three times larger than today.

Infrastructure investments can be large and costly, and their impact can be transformative for cities and regions for decades, if not centuries. So planning and evaluating these investments involves evaluating not only the technical and design aspects of the projects, but also the economic impact that they have on the affected regions, today and in the future. Simply using the current economic environment to do these evaluations, or incorporating naive growth projections that do not take the complex linkages between locations and the way they are affected by the project, will yield misleading results. Areas are linked through a variety of mechanisms including trade, commuting and migration, and it is important to incorporate their implications into the public and private decision-making process on infrastructure projects. Furthermore, if 'smart infrastructure' can enhance adaptability to some of the envisioned environmental and economic changes, it is important to determine the dimensions where flexibility is more relevant.

In the past, one issue with including a more detailed evaluation of the effect of infrastructure on the economic environment and its evolution was that incorporating a realistic set of links was complicated and impractical. Economics had not developed reliable quantitative models to do so. In the last two decades, this has changed dramatically. Today, there is a set of models of the distribution of economic activity that incorporate these and other channels as well as their dynamics. Furthermore, these models can be quantified using detailed data at a variety of levels of aggregation. So the analysis can evaluate the effect of a new road in a region, or a new subway line in a city. Furthermore, these models have been shown to perform well and to match a variety of strong regularities in the data, like the 'gravity equation' (the tight log-linear relationship between trade flows and trade costs, as well as commuting flows and commuting costs). In a recent survey, Redding and Rossi-Hansberg (2017) term these new models and quantification methodologies 'quantitative spatial economics'.
Using these more elaborate models to do a more detailed evaluation of infrastructure projects is extremely important. The world and the location of economic activity are in constant flux. One source of these fluctuations is that regions specialise in particular industries, and the importance of these industries in total output and employment varies over time. Coal-based energy production and heavy manufacturing are salient examples. In Europe and North America, the regions that specialised in modern manufacturing production at the beginning of the twentieth century are suffering today. Factories moved out of cities and employment shares in these industries went down as a result of technological change, international trade and offshoring. The result was a set of declining cities with urban infrastructure unsuitable to their current size. In the second half of the twentieth century, cities such as Detroit and Saint Louis in the USA shrank dramatically, leaving them today with an impractical and expensive urban structure that makes attracting modern firms in thriving sectors hard. The infrastructure projects of the past are therefore misused and underutilised. Urban infrastructure is wasted, at best, and a barrier for development, at worst.

The future will likely see the observed fluctuations in the size of cities increase even further. Phenomena associated with climate change, such as global warming and coastal flooding, will likely dramatically change the spatial distribution of population in the world. Cities in warmer locations and in some coastal areas will suffer, while those in colder areas that are more protected from flooding and extreme weather events will thrive. Planning urban infrastructure projects that will last for a century, without taking these predicted shifts in the distribution of population, makes no practical sense. These shocks and their dynamic implications can affect the economic viability of private and public infrastructure investments dramatically.

Schematically, in evaluating new infrastructure projects, one needs to take three dynamic effects, and their spatial consequences, into 
account. First, one needs to incorporate secular changes in the economic environment, like the structural transformation that has reduced manufacturing employment or climate change. Second, one needs to take into account the natural dynamic evolution of the economy as it invests and innovates. For example, with current migration frictions, one would expect that future production will be relatively more concentrated in India and China than in today's developed economies (as argued by Desmet et al. (2017)). Of course, these trends depend on trade and migration policies, among others. Third, one needs to take into account the actual effect of the infrastructure investment on the economic environments and its evolution. Although more work is still required to develop frameworks that incorporate all these channels in a practical way that can be readily used by teams evaluating particular infrastructure projects, a lot has been achieved, and practical models are available already.

The case for doing the evaluation correctly, and for investing in doing it better, is overwhelming, not only from a private or local public finance perspective, but also from a regional and a national one. Badly designed infrastructure projects can not only misuse the resources devoted to them, but can also transform the economic environment in ways that make it less flexible to shocks and secular trends. Locations might fail to adapt due to past infrastructure investments. The city of Detroit is a case in point.

The city of Detroit is well known as the centre of the US car manufacturing industry. Once famous as a centre of innovation, where Ford first used the production line to manufacture the famous Model $\mathrm{T}$ car, today the city is in disarray. Detroit's metropolitan area grew in population until the 1950s, when its population peaked at 1.8 million. Today, it has a population of less than 700000 . This dramatic decline has many causes. However, the decline in manufacturing employment in the car industry, due to new technologies and the relocation of car plants to the south of the USA and to other countries, is undoubtedly an important factor. The decline in the size of the city has left it misshapen and impractical. A core of employment at the centre of the city is surrounded by blight and vacant parcels. Instead of living in these close-by empty parcels, downtown workers live mostly in faraway suburbs, thereby incurring substantial commuting costs. Why are these vacant areas around downtown Detroit not redeveloped as residential areas for downtown workers? Why do other thriving industries not locate in the city of Detroit to take advantage of its urban infrastructure built to house three times the current population?

Owens et al. (2017) argue that a likely culprit for this ill-shaped urban form is the difficulty of coordinating residential developers. Due to a residential externality, neighbourhoods can be in two equilibria. One equilibrium features coordinated development, where residential developers construct housing and a sufficient number of residents decide to live in the neighbourhood to make it feasible and desirable. And another equilibrium is where the neighbourhood is vacant and no developer or resident wants to be the first to enter the neighbourhood. The ring of vacant lots in Detroit was initially developed for residential purposes in the 1920 s and was fully utilised for residential purposes in the 1950s. However, a system of radial highways connecting downtown neighbourhoods with the suburbs made coordination in these areas harder. Suburbs became relatively more attractive options for white-collar downtown workers, and the areas around downtown became increasingly poor and segregated. The Detroit riots in 1967 ended up coordinating the neighbourhoods in the vacant equilibrium, resulting in no new investment by developers and a large population exodus. Since then, more than 130000 housing units have been demolished in these neighbourhoods, but the area has attracted no new investment.

Importantly, it was the construction of a system of limited-access highways that made the redevelopment of these neighbourhoods harder. They increased the necessary scale for coordination and resulted in a city that is not attractive for new industries: a relatively small city where commuting distances are as large as in a much larger one. They created a city that has a ring of blight and the corresponding social problems, in between the areas where people work and where they live. It is hard to know the extent to which these neighbourhoods would have redeveloped in the absence of these highways, but it seems clear that they made the benefits of coordination smaller, thereby requiring a larger scale to develop them profitably. Today, successful development requires many developers because it requires building not only many residences for downtown workers, but also complementary highquality urban infrastructure, schools and other urban amenities. Furthermore, it requires coordination with the city that provides security and basic services like sewage, electricity and water that, in some of these areas, have been discontinued, at least partially.

Still, one can envision policies that could improve the current allocation by coordinating these neighbourhoods in the development equilibrium. One such example is a policy of 'investment guarantees'. The government, or any credible institution, guarantees a level of development in the neighbourhood hoping to attract enough private investment. If sufficient private investment is attracted, the guarantee is not exercised; otherwise, the government invests the difference between the guarantee and the realised private investment. If the magnitude of these guarantees is sufficiently high, developers will feel confident and enter, and the residential areas will be developed at no cost to the government. Of course, it is important to choose the magnitude of these guarantees correctly. If too large, they will imply a waste of resources since private investment will not be sufficient to make them irrelevant; if too small, the neighbourhood will not be developed.

Using the quantitative spatial economics' methodology, augmented with this neighbourhood residential coordination mechanism, Owens et al. (2017) quantify the size of these guarantees and the impact that they can have on the city of Detroit. Out of the more than 1000 census tracts in Detroit's metropolitan area, 52 are found to be essentially vacant and potentially subject to the policy. 
Smart Infrastructure and Construction

Volume 170 Issue SC1
Briefing: Infrastructure projects and the

flexibility of urban infrastructure

Rossi-Hansberg
Coordinating all 52 tracts with development guarantees implies a guarantee of about US\$100 million (2014) and yields an increase in business and residential land rents of about US\$170 million per year in the city of Detroit and US\$300 million per year in the Detroit metropolitan area. The treated tracts obtain most of the increase in residential rents but only a small fraction of the increase in business rents, which are distributed throughout the city.

These gains are large. They illustrate how good policy, together with careful economic evaluation, can ameliorate the impact of bad shocks and the legacy of infrastructure projects optimised for a long-gone past The tools to do the necessary analysis have been, or are in the process of being, developed. It is now the turn of city planners and private developers to realise their value and use them productively to plan the future 'smart infrastructure' projects.

\section{REFERENCES}

Desmet K, Nagy D and Rossi-Hansberg E (2017) The geography of development. Journal of Political Economy (in press).

Owens R, Rossi-Hansberg E and Sarte P (2017) Rethinking Detroit. Princeton University, Princeton, NJ, USA.

Redding S and Rossi-Hansberg E (2017) Quantitative spatial economics. Annual Review of Economics, http://dx.doi.org/10.1146/annureveconomics-063016-103713.

\section{How can you contribute?}

To discuss this paper, please email up to 500 words to the editor at journals@ice.org.uk. Your contribution will be forwarded to the author(s) for a reply and, if considered appropriate by the editorial board, it will be published as discussion in a future issue of the journal.

Proceedings journals rely entirely on contributions from the civil engineering profession (and allied disciplines).

Information about how to email your paper online is available at www.icevirtuallibrary.com/page/authors, where you will also find detailed author guidelines. 